\title{
Experimental analysis of Perfobond shear connection between steel and lightweight concrete
}

\author{
Isabel Valente*, Paulo J.S. Cruz \\ Civil Engineering Department, University of Minho, Azurém, Guimarães 4800-058, Portugal
}

\begin{abstract}
This paper describes the experimental tests carried out at the University of Minho using Perfobond connectors and lightweight concrete. The main objective of these tests is to describe the connection behaviour and to analyse and compare the contribution of the different elements to the slip measured between the steel profile and the concrete slab. In this way, it is possible to define the connection ductility. The test configuration follows some of the EC4 recommendations and repeats some dispositions referred to by Oguejiofor and Ferreira. The parameters under study are the concrete strength, the reinforcement disposition and the Perfobond rib existence and spacing of holes. An important comparison with the experimental results achieved by different authors using normal weight concrete may then be established.

(C) 2003 Elsevier Ltd. All rights reserved.
\end{abstract}

Keywords: Perfobond rib shear connector; Lightweight concrete

\section{Introduction}

The use of composite steel structures accounts for the contribution of the two materials, provided a composite action exists between the concrete and steel members. A composite action can be obtained, reducing or preventing the relative displacement of concrete and steel sections at their interface. Shear connectors are usually added to provide this composite action. The strength and stiffness of a composite section depends on the degree of composite action between concrete and steel components. The degree of composite action is related to the geometrical and mechanical properties of the shear connectors and the concrete slab.

\footnotetext{
* Corresponding author. 
The desire of a good solution with minimum costs enhanced development of new products. The most common types now in use are the shear studs, the Perfobond rib and the T-type (Fig. 1). The experimental work presented in the following was carried out to establish the behaviour of the Perfobond rib connector when lightweight concrete is used.

The Perfobond rib shear connector was first developed by the German firm Leonhardt, Andrå, and Partners of Stuttgart for the third bridge over the Caroni river in Venezuela. It consists of a steel plate, with a limited number of holes, welded to the steel beam and concreted inside the slab. During the casting, the plate openings are filled with concrete, forming dowels that provide resistance to horizontal shear and prevent vertical separation between the steel beam and the concrete slab (Fig. 2).

According to the dispositions defined in Eurocode 4 [1], the push-out specimens consist of a steel beam section held in the vertical position by two identical concrete slabs (Fig. 2b). The concrete slabs are attached to the beam by shear connectors. The connection is subjected to a vertical load, which produces a shear load along the interface between the concrete slab and the beam flange on both sides.

A considerable amount of experimental tests have been done to establish the behaviour of different types of shear connectors. Galjaard and Walraven [2] performed tests using shear studs, Perfobond connectors, T-connectors and oscillating Perfobond connectors, both with normal weight and lightweight concrete. Hegger et al. $[3,4]$ used normal shear studs and several modified shear studs, T-connectors and T-bulb connectors on normal weight concrete. Oguejiofor and Hosain $[5,6]$ carried out an extensive experimental study with different Perfobond connector geometries on normal weight concrete. Ferreira [7] conducted tests with Perfobond connectors on normal weight concrete for building structures and Machacek and Studnicka [8] conducted several tests with a modified Perfobond connector, using both normal weight and lightweight concrete.

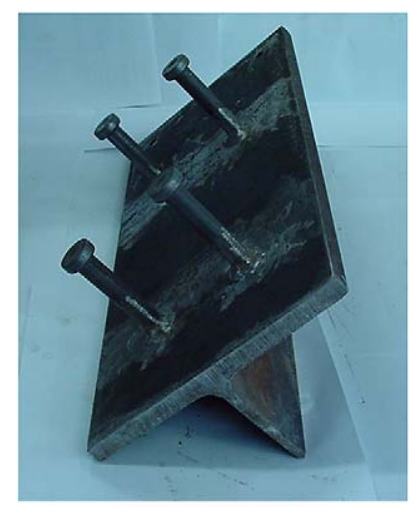

Shear studs

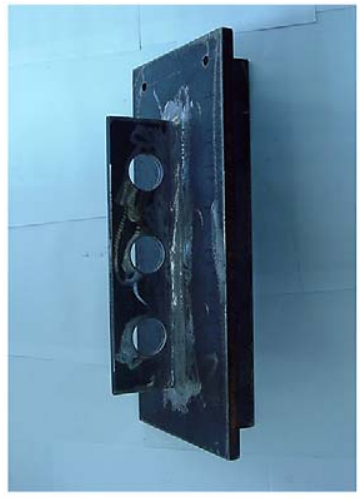

Perfobond connector

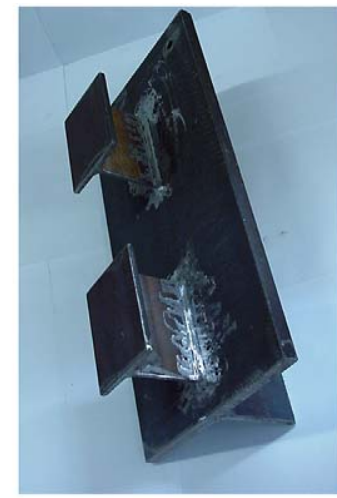

$\mathrm{T}$ connector

Fig. 1. Connectors types. 


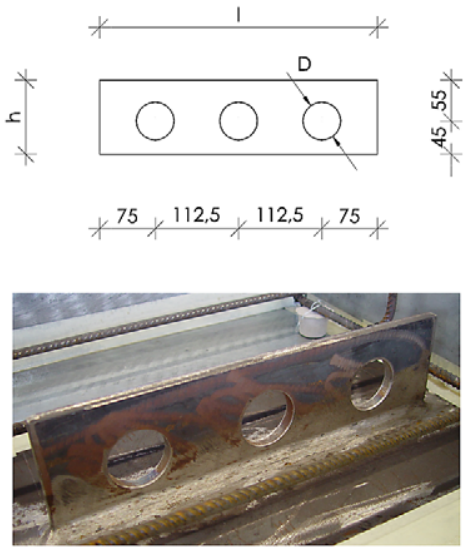

a) Perfobond rib

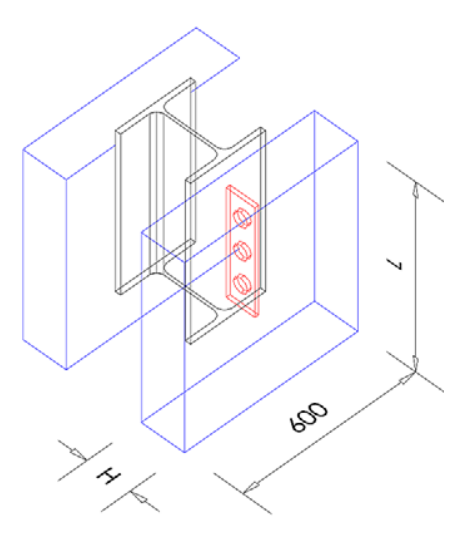

b) Specimen

Fig. 2. Specimen configuration: (a) Perfobond rib; (b) specimen.

\section{Resistance capacity of the Perfobond connection}

Based on a regression analysis of the results of normal weight concrete specimens, with different connector geometries and reinforcement distribution, Oguejiofor and Hosain [6] established expression (1), which quantifies the resistance capacity of the shear connection. This expression accounts for the contribution of three essential parameters: the concrete slab subjected to shear, the transversal reinforcement and the concrete dowels passing through the Perfobond rib holes:

$$
q_{\mathrm{u}}=0.590 A_{\mathrm{c}} \sqrt{f_{\mathrm{c}}^{\prime}}+1.233 A_{\mathrm{tr}} f_{\mathrm{y}}+2.871 n d^{2} \sqrt{f_{\mathrm{c}}^{\prime}}
$$

where $f_{\mathrm{c}}^{\prime}$ is the concrete compressive strength, $f_{\mathrm{y}}$ the steel yield strength, $A_{\mathrm{c}}$ the concrete shear area, $A_{\mathrm{tr}}$ the area of transversal reinforcement that pass through holes, $d$ the diameter of the Perfobond rib holes and $n$ is the number of Perfobond rib holes.

After proposing Eq. (1), the same author conducted more tests and established a new expression, (2), that could quantify better the shear connection resistance capacity, according to his experimental results. The first part of this new equation differs from the first part of expression (1), as it refers to the local resistance under the Perfobond connector,

$$
q_{\mathrm{u}}=4.5 h t f_{\mathrm{c}}^{\prime}+0.91 A_{\mathrm{tr}} f_{\mathrm{y}}+3.31 n d^{2} \sqrt{f_{\mathrm{c}}^{\prime}}
$$

where $h$ is the rib height, $t$ the thickness, $A_{\text {tr }}$ the total area of transversal reinforcement and the other parameters are the same as in Eq. (1).

In Table 1, a comparison between the predicted and ultimate load of 16 tests performed with normal weight concrete specimens is presented [5-7]. The specimens presented in Table 1 are similar to those tested and presented in this paper. 


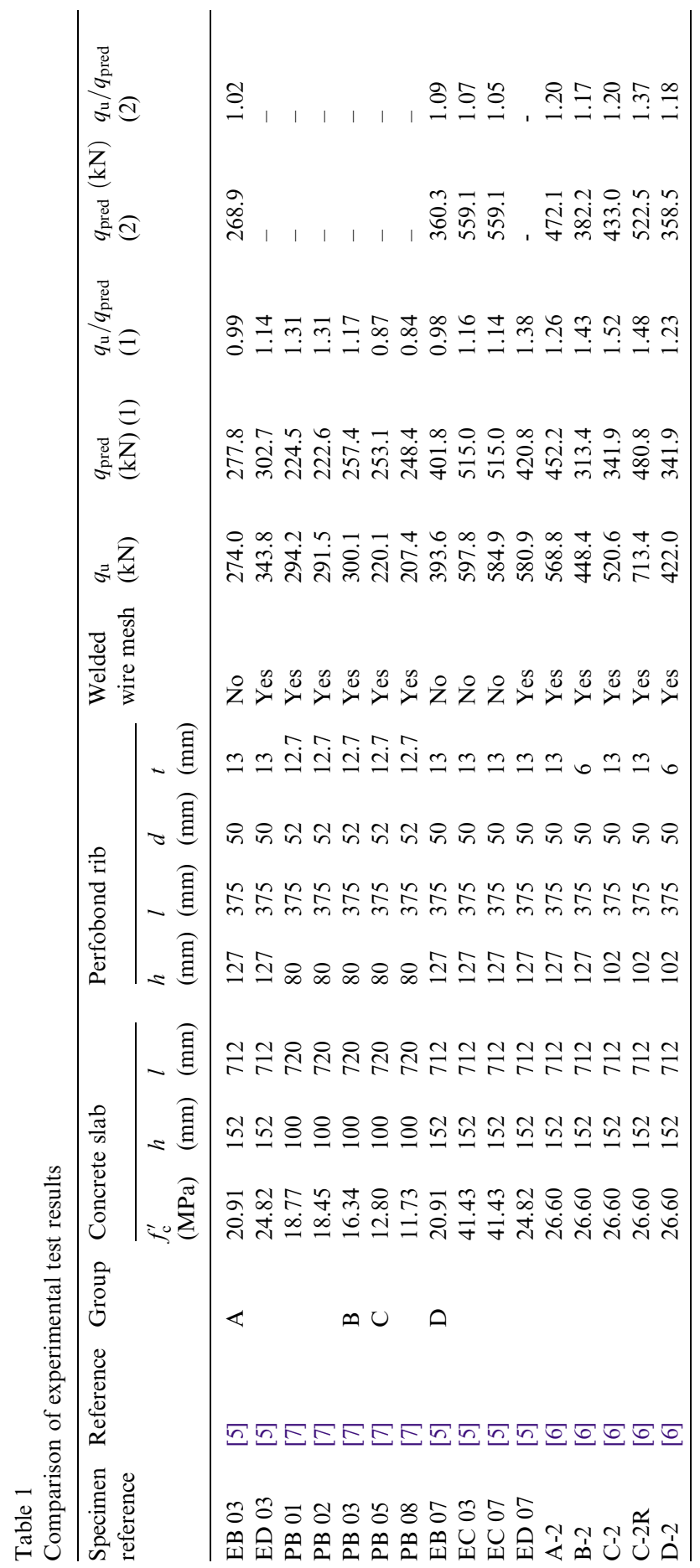


The division into groups presented in Table 1 gives a comparison with the experimental work performed and presented in this paper, as shown later in Section 3 and Fig. 6.

\section{Test setup}

In order to quantify the resistance capacity of the Perfobond shear connection on lightweight concrete and assess the accuracy of Eqs. (1) and (2) in predicting the behaviour of this shear connection, an extensive experimental program is being developed at the Civil Engineering Laboratory of University of Minho [9]. The tests that were already performed and will be performed in the near future try to isolate the different components of the connection in order to establish the importance of each one.

The connector types and the specimen geometry are shown in Fig. 3 indicating Perfobond connectors, shear stud connectors and T-connectors.

To simulate better the conditions in a real structure (composite beam or slab), both slabs should be concreted simultaneously in a horizontal position, which implies cutting the steel beam into two halves (Fig. 4).

After concrete hardening, it is possible to put both slabs in vertical position and then weld the two HEB260 half webs.

To evaluate the reinforcement distribution, the concrete resistance was intended to be approximately the same. This could not be completely accomplished, because each specimen was cast in a different day, but the differences are very small.

A vertical monotonic load was applied to the specimens using a hydraulic test machine with a $5000 \mathrm{kN}$ capacity. The load was applied in increments and the vertical slip at the steel to concrete interface was measured at two points at regular intervals of time. The lateral displacement of the slabs was also measured.

To reduce the effect of some imperfections, neoprene sheeting was placed at the base of the concrete slabs. Two steel plates with two greased Teflon sheets between them were used, under neoprene, to eliminate the lateral confinement produced by friction between the slab and the testing machine.
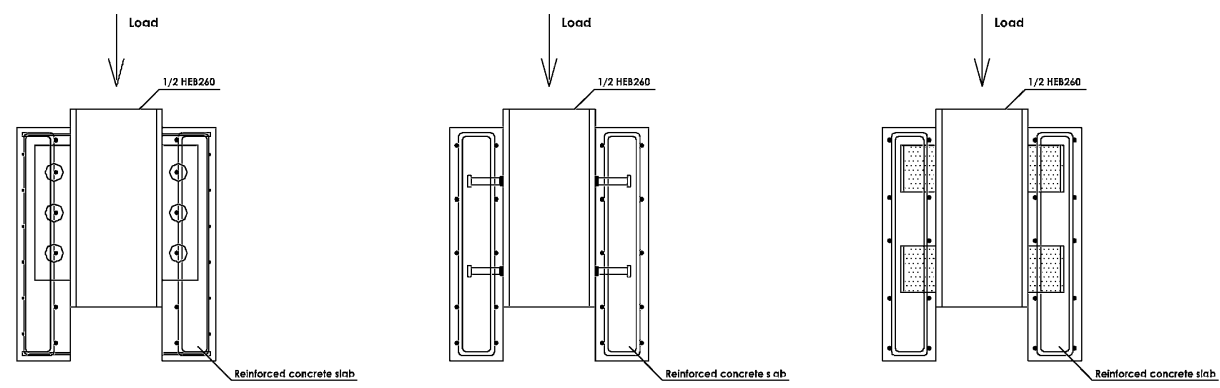

Fig. 3. Configuration of the specimens to be tested at the University of Minho, Portugal. 

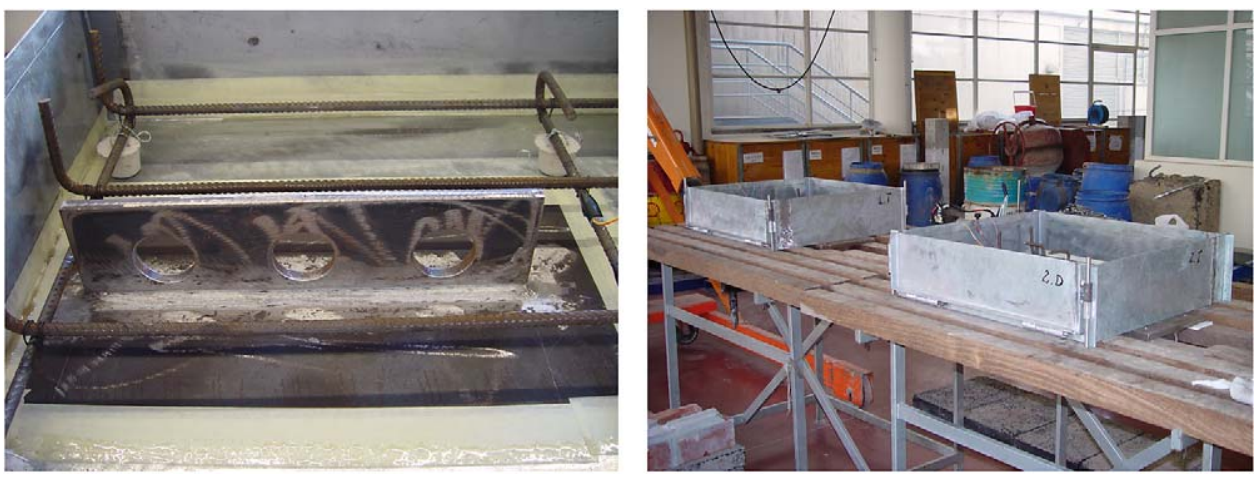

Fig. 4. Casting conditions.

The test setup is shown in Fig. 5. The testing machine consists of a pair of rigid steel plates with $200 \mathrm{~mm}$ width separated by four steel hollow cylinders of $275 \mathrm{~mm}$ diameter, $25 \mathrm{~mm}$ width and $1150 \mathrm{~mm}$ height. The cylinders and joints between cylinders and plates are pre-stressed.

The connector geometry is the same in every specimen and has the dimensions of $375 \times 100 \times 13 \mathrm{~mm}^{3}$. The slab dimensions are $650 \times 600 \times 150 \mathrm{~mm}^{3}$. In specimen CP3.1, there is a hole in the slab, beginning right under the Perfobond rib and end-
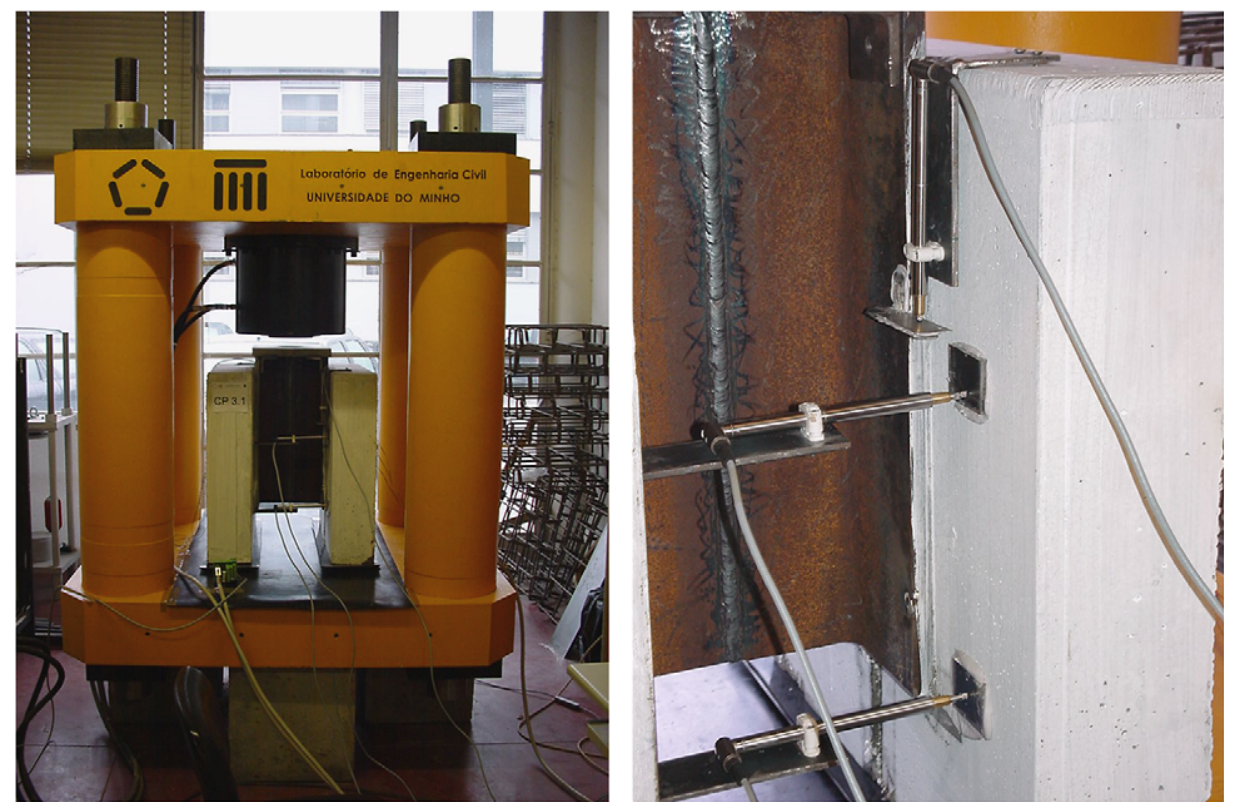

Fig. 5. Push-out test setup and measurement settings. 

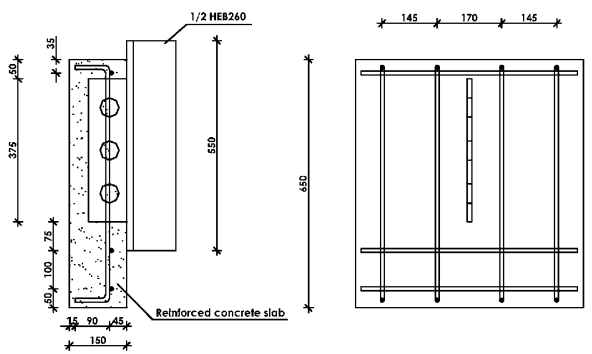

a) $\mathrm{CP} 1.1$
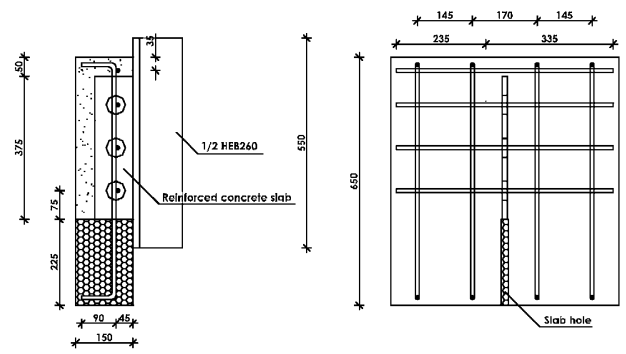

c) $\mathrm{CP} 3.1$
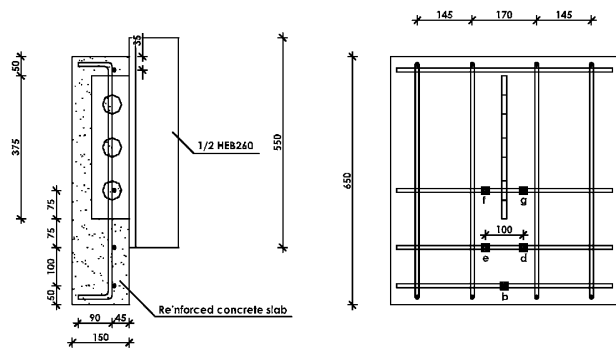

b) $\mathrm{CP} 2.1$
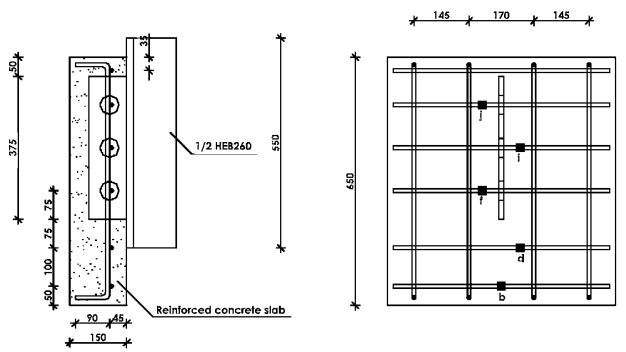

d) $\mathrm{CP} 4.1$

Fig. 6. Configuration of the push-out test specimens: (a) CP1.1; (b) CP2.1; (c) CP3.1; (d) CP4.1.

ing at its bottom. The slab reinforcement is made of $10 \mathrm{~mm}$ bar and none of the specimens has a distributed top slab mesh.

The basis for this work with Perfobond rib shear connector was: the dispositions defined in Eurocode 4 [1], the experimental study performed by Oguejiofor and Hosain [5,6], which involved tests on 58 specimens with different connectors geometries and reinforcement distribution and the work of Ferreira [7], which involved tests on eight specimens with the same connector geometry and different reinforcement distribution. Other types of connectors (shear studs and T-type) will also be tested in the near future.

Both Galjaard and Walraven [2] and Machacek and Studnicka [8] tested Perfobond specimens with lightweight concrete. The configuration of their tests is not the same as the one chosen for this work; hence, the results are not directly comparable, although a good relation could be noticed with Machacek results [8] in terms of failure load values.

The experimental work involved the testing of push-out specimens (Fig. 6). These specimens are, respectively, similar to the tested specimens presented in Table 1: CP1-Group A; CP2-Group B, CP3-Group C and CP4 Group D. 


\section{Experimental behaviour of the tested specimens}

\subsection{Failure mechanisms}

All the failure mechanisms observed were associated with the failure of the concrete slabs. The Perfobond rib shear connectors and the respective welding were intact or almost intact at the end of the tests.

The specimen failure began with a longitudinal crack on the concrete slab. The crack began at the bottom of the slab and progressively grew towards the top of this element with the increase of load. The crack was positioned close to the Perfobond rib (Fig. 7).

After the testing, the specimens were destroyed in order to observe the effect of loading on the concrete slab, Perfobond rib and reinforcement.

In general, the Perfobond rib was intact, with an exception of its lowest part, where some lateral distortion can be seen (Fig. 8). In the longitudinal splitting zone, the concrete surface shows two different aspects: close to the Perfobond rib, the concrete surface is very smooth, showing little or no adherence to the rib. On the other hand, in front of the rib, the concrete surface is rough, showing that splitting occurred when the failure of the aggregate (expanded clay) occurred (Fig. 8).

\subsection{Reinforcement}

In the tests performed by Oguejiofor and Walraven [5], there were specimens with no transversal reinforcement. A sudden failure due to longitudinal splitting is mentioned, occurring instantaneously on the entire length of the concrete slab. When this happened, the specimens lost all ability to sustain the load. All the tested specimens had some transversal reinforcement. The longitudinal crack begins at
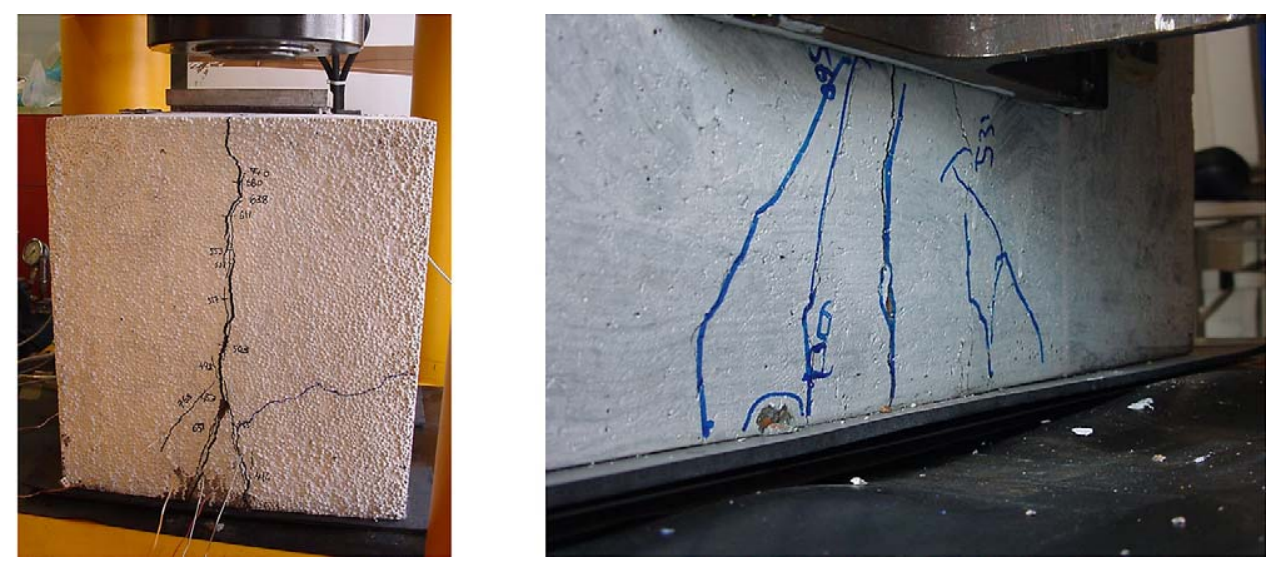

Fig. 7. Longitudinal cracking. 


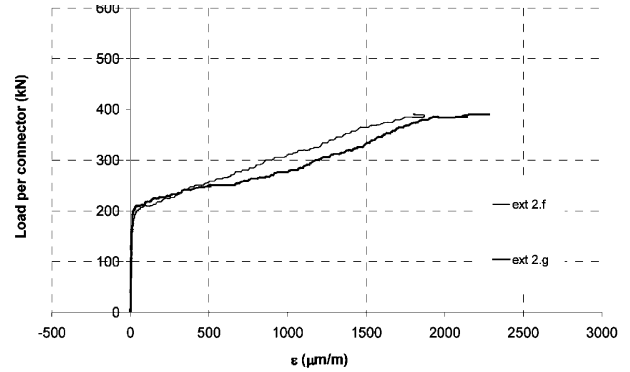

a) $\mathrm{CP} 2.1$

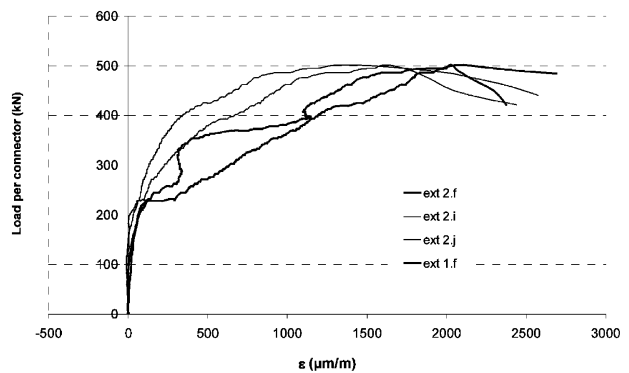

b) CP4.1

Fig. 8. Reinforcement strain: (a) CP2.1; (b) CP4.1.

the bottom of the concrete slab and the longitudinal crack growth could be observed (Fig. 7).

To measure strain evolution during the tests, strain gauges were fixed to the slab reinforcement in some of the specimens. Until the cracking occurs, the measured strains are very reduced. When the cracking begins, the strains rapidly grow, showing the importance of the reinforcement existence at this moment. The measured strain values at failure load show that the reinforcement is close to yielding. The cracking load value is quite similar in both tests as can be observed, and the failure load value depends on the reinforcement presence.

So, it can be noticed that the transversal reinforcement plays an important part in reducing the crack width, in sustaining the load and in the end of the test permitting a more ductile behaviour of the connection.

The importance of the transversal reinforcement positioned in front of the Perfobond rib may as well be observed. This reinforcement reduces and controls the crack development during the test.

A very important role was also played by the transversal reinforcement, in terms of load capacity. When this reinforcement area was increased, the failure load value was superior (Fig. 10 and Table 2).

It can be noticed that the reinforcement positioned under the Perfobond rib suffered some bending, although it was not pronounced (Fig. 9). At this location, the vertical load, also resisted by the concrete slab, was distributed up to the slab base, with general cracking of this zone (Fig. 7).

Table 2

Experimental test results

\begin{tabular}{llll}
\hline Specimen number & ${f^{\prime}}_{\mathrm{c}}(\mathrm{MPa})$ & $q_{\mathrm{u}}(\mathrm{kN})($ per connector $)$ & $\delta_{\mathrm{u}}(\mathrm{mm})$ \\
\hline CP 1.1 & 60.30 & 317.7 & 1.68 \\
CP 2.1 & 59.24 & 390.6 & 1.39 \\
CP 3.1 & 60.46 & 237.7 & 2.20 \\
CP 4.1 & 64.24 & 502.1 & 1.58 \\
\hline
\end{tabular}



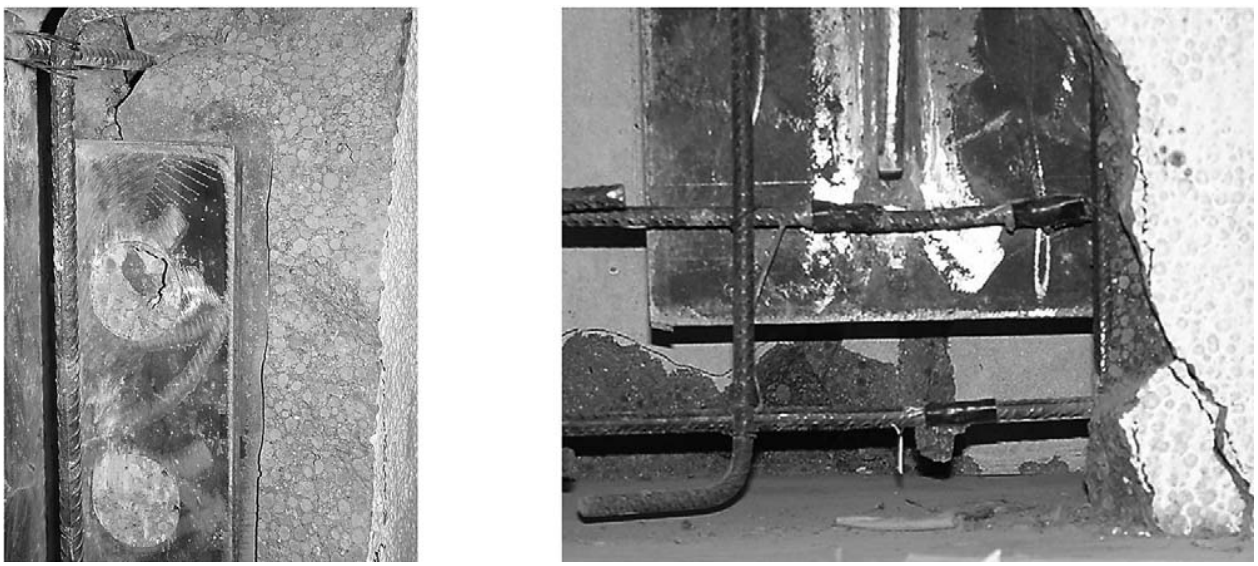

Fig. 9. Concrete failure.

\subsection{Failure load and ductility}

It can be concluded that the failure occurred with complete progression of the longitudinal crack up to the top of the slab, the concrete smashing under the Perfobond rib (except for CP3.1) and an uncontrolled slip between the steel profile and the concrete slab.

Fig. 10 and Table 2 show that the average slip measured during the tests was reduced, especially during the initial load increments. Eurocode 4 [1] defines ductile connectors as those with sufficient deformation capacity to justify the assumption of ideal plastic behaviour of the shear connection in the structure considered. It also refers a minimum characteristic slip capacity of $6 \mathrm{~mm}$ corresponding to the characteristic load. The characteristic load is defined as the minimum failure load, reduced by $10 \%$ of its value. In these tests, the failure occurs immediately after the

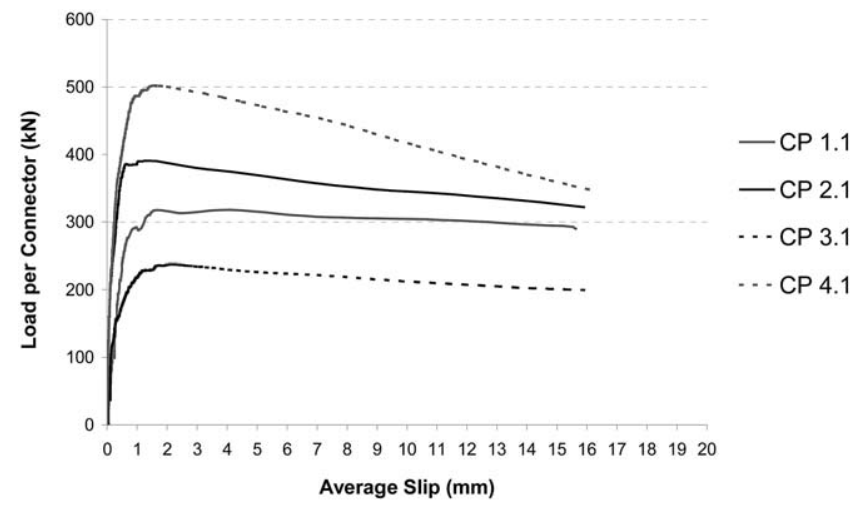

Fig. 10. Load vs. average slip between concrete slab and metallic profile. 


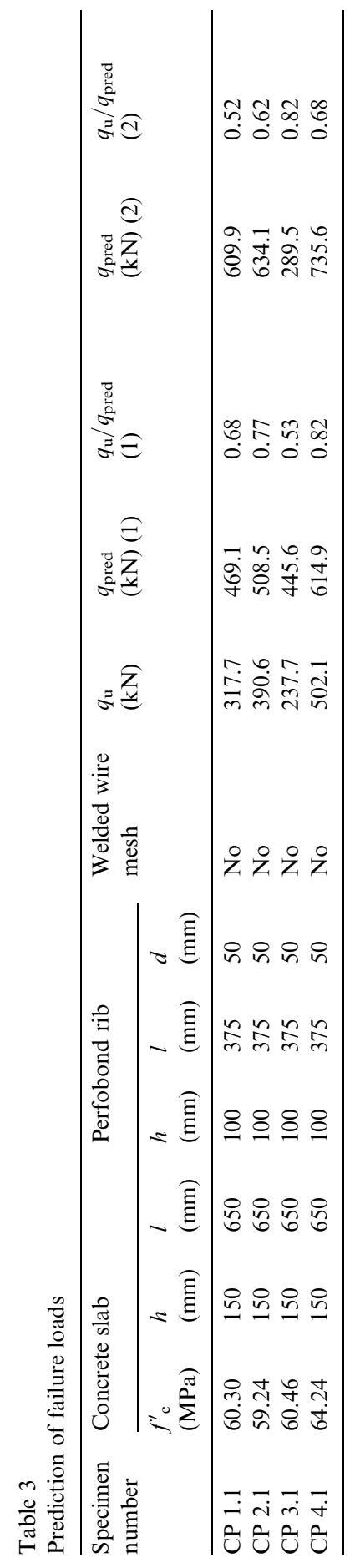


maximum load is reached. So, the maximum slip is considered as the one corresponding to the maximum load because the slip rapidly increases to very high values after the maximum load is reached. The slip values measured after the maximum load are not considered.

Comparing the values of the maximum slip presented in Table 2 with the minimum slip of $6 \mathrm{~mm}$ established in Eurocode 4 in order to permit a partial connection, it becomes clear that this type of connector can only be used with total connection and does not guarantee a ductile behaviour. Other experimental testing $[5,6]$ proved that the use of a welded wire mesh, positioned in the top of the concrete slab, makes it possible to have a superior maximum load associated with a higher value of the concrete to steel slip.

The tests were performed with load control, due to some limitations of the testing machine at the time. It is possible that the values measured for slip are smaller than those that would be attained with displacement control.

The lateral displacement measured during the tests was very low, only noticeable when slab splitting occurred.

When the reinforcement area was increased, the failure load value was superior. However, the respective measured slip between the steel profile and the concrete slab was approximately the same. The use of more transversal reinforcement resulted in an increase of resistance but not in ductility.

\subsection{Numerical evaluation}

As far as the tests performed can show, Eqs. (1) and (2) give not so good results when applied to lightweight concrete. Table 3 shows the relation between the maximum load value predicted and the experimental load value measured for the tests performed. The ultimate load predicted is always smaller than the experimental load measured during the tests performed. It is though convenient to perform more tests to fully analyse this connection behaviour and if it is the case, to propose a new expression that better predicts the value of the ultimate load.

Table 4 shows the contribution of each part of Eqs. (1) and (2) applied to the tested specimens. The failure load values measured experimentally were always inferior to those predicted with Eqs. (1) and (2). A decrease of at least $20 \%$ of the predicted failure load can be observed.

The difference measured between the experimental value and the predicted value for CP2.1 and CP4.1 was very similar, but in comparison, testing specimen CP1.1 resulted in a lower failure load. Probably Eqs. (1) and (2) can quantify the contribution of the transversal reinforcement in a correct way $\left(q_{2}\right)$ and a new approach would have to be studied to evaluate the contribution of lightweight concrete.

The predicted failure load value for specimen CP3.1 was far from the experimental value when Eq. (1) is considered. This was not observed in the tests performed by Ferreira [7] (Table 1-PB05, PB08), where the two values were approximately the same. It can be noticed that CP3.1 geometry was different from the rest of the specimens and that the failure mechanisms had also noticeable differences. 


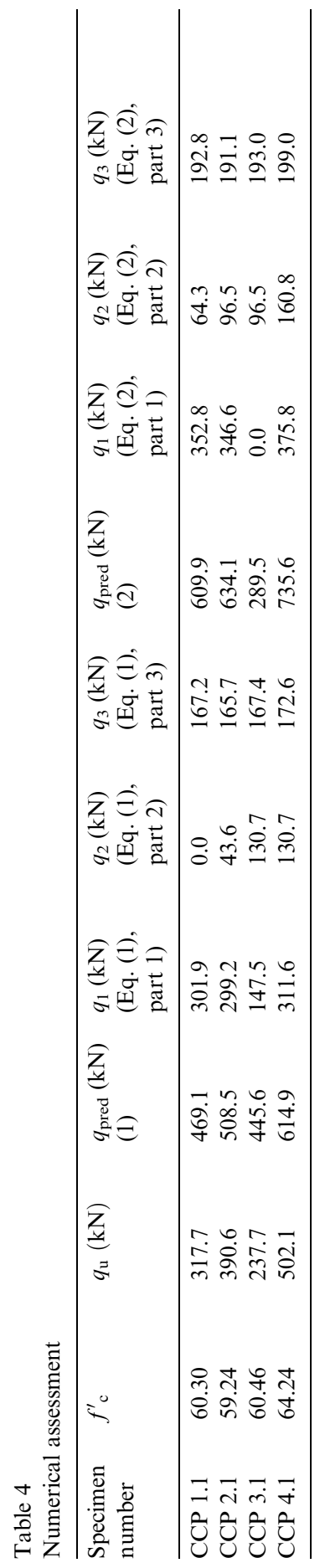




\section{Conclusions}

The experimental work performed made it possible to observe the behaviour of the steel to lightweight concrete connection with Perfobond rib shear connector. The specimens tested showed some differences of behaviour when compared to normal weight concrete specimens, which will have to be quantified with further testing. These tests are currently being executed at the Structural Civil Engineering Laboratory of the University of Minho.

The tests showed that the failure mechanisms observed were associated with the failure of the concrete slabs, with little or no deformation of the Perfobond rib. The failure occurred with the complete progression of a longitudinal crack until the top of the slab, the concrete smashing under the Perfobond rib and an uncontrolled slip between the metallic profile and the concrete slab. The average slip between the concrete slab and the steel beam measured for the maximum load was reduced and subsequently increased, showing that this type of connector does not guarantee a ductile behaviour.

As far as the tests performed can show, Eqs. (1) and (2) do not give such good results when applied to lightweight concrete. The ultimate load predicted is always smaller than the experimental load measured during the tests performed. It is though convenient to perform more tests to fully analyse this connection behaviour and, if it is the case, to propose a new expression that predicts better the value of the ultimate load.

\section{Acknowledgements}

The present work was financed by the investigation project Sapiens ECM/ 33067/99 - "Steel-concrete composite bridges: use of lightweight high performance concrete" from program PRAXIS XXI. We also thank the Structural Civil Engineering Laboratory of the University of Minho, where the tests were performed.

\section{References}

[1] Eurocode 4. ENV 1994. Design of composite steel and concrete structures. European Committee for Standardisation (CEN), 1997; 1994.

[2] Galjaard JC, Walraven JC. Behavior of shear connector devices for lightweight steel-concrete composite structures - results, observations and comparisons of static tests. Second International Symposium on Structural Lightweight Aggregate Concrete, Kristiansand, Norway, 18-22 June. 2000, p. 221-30.

[3] Abschlussbericht zum Forschungsvorhaben "Untersuchungen zur Duktilität der Verbundmittel bei Anwendung vor hochfestem Stahl und hochfestem Beton"; AIF-No.12124; Aachen, November 2000.

[4] Hegger J, Sedlacek G, Döinghaus P, Trumpf H. Studies on the ductility of shear connectors when using high-strength concrete. International Symposium on Connections between Steel and Concrete, University of Stuttgart, 10-12 September 2001, vol. 2, p. 1025-45.

[5] Oguejiofor EC, Hosain MU. A parametric study of perfobond rib shear connectors. Can J Civil Eng 1994;21:614-25. 
[6] Oguejiofor EC, Hosain MU. Numerical analysis of Push-Out specimens with Perfobond rib connectors. Comp Struct 1996;62(4):617-24.

[7] Ferreira LTS. Sistemas construtivos semi-rígidos mistos para edificações. PhD thesis. Pontifícia Universidade Católica do Rio de Janeiro, Brasil. April 2000

[8] Machacek J, Studnicka J. Perforated shear connectors. Steel Comp Struct 2002;2(1):51-66.

[9] Valente I, Cruz PJS. Análise experimental da conexão aço-betão. III Encontro Nacional de Construç ão Metálica e Mista, 5-6 December 2001, Aveiro, Portugal, p. 321-30. 